\title{
«НОВЫЙ ГОРОДСКОЙ АКТИВИЗМ» И «ПУБЛИЧНАЯ ПОЛИТИКА" В РОССИИ (НА ПРИМЕРЕ САНКТ-ПЕТЕРБУРГА)
}

\begin{abstract}
На протяжении последних десяти лет мы (в качестве исследователей и консультантов или участников городских активистских проектов) наблюдая изменения городского активизма в Санкт-Петербурге, выделили несколько векторов его развития. Различные формы интервенций в городские пространства, характерные для начала 2000-х- от микроинициатив в стиле «делай сам» $(D I Y)$ до практик тактического урбанизма, постепенно трансформируются в явление, которое мы называем «новый городской активизм». В статье мы покажем, как городские активисты переходят от протестных и защитных инициатив к созидательным, от противостояния - к широкому партнерству и сотрудничеству. Опираясь на интервью с активистами и наблюдения за проектами, реализованными в Петербурге, мы обнаруживаем, что нынешний «созидательный» городской активизм, уходящий корнями в увлечение урбанистикой, отличает легкая фестивальная атмосфера. Мы показываем также, какие тенденции градозащитного активизма, характерные для конца 1980-х-2000-х гг., новый городской активизм наследует, а в каких представляет из себя качественно новое явление. В заключении мы аргументируем тезис, что, даже не будучи «политически активными» в общепринятом значении этого слова, т.е. игнорируя привычные политические институты (такие как выборы) или институты контроля за деятельностью власти (такие как митинги и акции протеста), городские активисты тем не менее не могут считаться «аполитичными», поскольку формируют альтернативное пространство политического- сферу «публичной политики» (в духе Ханны Арендт). При этом город выступает для них
\end{abstract}

Олег Вячеславович Паченков- к.социол.н., руководитель проектов, Центр гуманистической урбанистики UP, Европейский университет в Санкт-Петербурге, Санкт-Петербург, Россия. Электронная почта: pachenkov@yahoo.com

Лилия Викторовна Воронкова- н.с., руководитель проектов, Центр независимых социологических исследований, Санкт-Петербург, Россия. Электронная почта: lilia.voron@gmail.com 
и как объединяющая «сверх-ценность», и как сцена, где их усилиями осуществляется политика нового типа, имеющая отчетливые черты «хорошо забытой старой» античной politika, осуществляемой от имени и во имя polis - своего города.

Ключевые слова: активизм, город, политика, публичная сфера, публичные пространства, урбанистика

DOI: 10.17323/727-0634-2021-19-2-253-268

В последние десятилетия наблюдается развитие феномена городского активизма в России. Различные низовые ситуативные формы интервенций в городские пространства трансформируются в явление, которое мы называем «новый городской активизм» (НГА). В статье показано, как новые городские активисты осознают себя как силу, которая может влиять на городские решения, какие форматы деятельности они для этого используют, и какими отличительными чертами обладают. Под «активизмом» мы предлагаем понимать активную жизненную позицию (часто именуемую в обыденном языке «небезразличием»), сопровождающуюся деятельностью (активностью), направленной на изменение социальной, культурной, политической, материальной реальности (в тех случаях, когда это не является «работой», т.е. источником регулярного дохода). Под «городским активизмом» мы понимаем такие его формы, в которых город, городское пространство и среда являются основным предметом внимания и приложения усилий активистов.

Уже в конце XX в. исследователи писали о «новых общественных движениях», возникающих в постиндустриальных обществах (Здравомыслова 1990, 1993). К ним принято относить «ценностные» движения: например, экологическое, феминистское, антивоенное (Халий 2007: 68). Применительно к российской ситуации Карин Клеман и ее коллеги (2010) использовали эпитет «новые» в отношении «постперестроечных» социальных движений, в особенности, характерных для середины 2000-х гг. Они уточняли, что

речь идет об условной «новизне» в сравнении со «старыми» формами общественной активности, такими как первомайские дефиле, обязательные профсоюзные или партийные собрания, бюрократические и официозные мероприятия, которые исполняли роль «приводных ремней» в механизме власти (там же: 81$)$.

В отличие от Клеман и коллег, мы фокусируемся на трансформации феномена городского активизма (а не на социальных и политических движениях в целом), и показываем, как смещаются его акценты и приоритеты, меняются характер и черты, позволяющие говорить о его «новом» состоянии.

Статья опирается на материалы, собранные авторами в ряде городских инициатив в Санкт-Петербурге с 2010 по 2020 гг. Материалы интервью 
собраны в рамках исследовательских проектов: «Качество городского пространства: векторы развития гражданских инициативных групп в России и Германии» (2016-2018, поддержка РГНФ; 15 интервью) и НИР «Новые данные о гражданах и власти: большие данные и качественная экспертиза» (2020), реализуемого при поддержке Фонда экономической политики (40 интервью). Наблюдая за развитием городского активизма в Петербурге на протяжении последних десяти лет, мы выделяем несколько векторов его трансформации. Следуя типологии, предложенной Борисом Гладаревым, к «предыдущим формациям» ленинградского-петербургского городского активизма мы относим «четыре волны»: 1900-1917, 1917-1932, 1986-1991, 2006-2010 (Гладарев 2011: 139-141). Основным отличием НГА от предыдущих волн, преимущественно градозащитных - является смена акцента деятельности с «охраны» на «созидание». Градозащитники выступают прежде всего за сохранение существующего (архитектурного наследия), а для «новых» городских активистов характерно стремление к изменениям и созданию в городе чего-то нового, связанного чаще всего, «непосредственно с физическим изменением городской среды» (Королева, Чернова 2018:93). «Охранный» и «созидательный» подходы не являются взаимоисключающими, однако мы предлагаем обратить внимание на формирование нового тренда, названного нами НГА- смещение от защиты существующих элементов культурного и архитектурного наследия к изменению городской среды через ее трансформацию и созидание.

Еще одна важная характеристика НГА связана с особой прагматикой и способностью новых активистов к кооперации. Участники право- и градозащитных движений конца 1980-х - нач. 2000-х ориентированы прежде всего на сотрудничество «со своими»- людьми одного круга. Для них характерна риторика противостояния городским властям, стремление «контролировать», принудить их к отказу от неприемлемых действий (Гладарев 2011: 196-198). Новые городские активисты, напротив, готовы к кооперации с очень широким кругом контрагентов, включая бизнесменов (девелоперов) и чиновников, с которыми они могут не разделять большинства ценностей. За этой готовностью к коммуникации стоит убежденность в том, что для достижения целей по трансформации городской среды диалог эффективнее, чем открытое противостояние. Стремление к общему благу (чему-то важному и нужному горожанам) является ключевой ценностью, вокруг которой строится деятельность новых активистов. Именно такие ценности (а не «беспринципность») обуславливают возможность взаимодействия новых активистов с теми, кого классические градозащитные активисты считают «идеологическими противниками».

Мы осмысливаем НГА в контексте более широких общественных и политических процессов и показываем, что город становится пространством, где усилиями якобы «аполитичных» городских активистов в действительности осуществляется политика иного типа. Эта политика 
не связанна с национальным государством и его институтами, но представляет собой публичную деятельность в городе и для города, осуществляемую силами активных горожан в духе vita activa (Арендт 2000). Мы описываем упомянутые выше тренды на примере Санкт-Петербурга, опираясь на методологию кейс-стади. Не претендуя на экстраполяцию выводов, однако рассчитываем на дискуссию о распространенности описываемых процессов в других городах страны.

\section{Движения «делай сам" и «тактический урбанизм» как источники нового городского активизма}

Начало XXI в. в российских городах охарактеризовалось подъемом различных социальных движений, отчасти продолживших политические движения 1980-90-х гг., отчасти сформировавшихся как реакция на современную политику (например, протесты против монетизации льгот или «Болотная») или как экологические движения под влиянием глобального контекста (Романов, Ярская-Смирнова 2009; Клеман и др. 2010: 83104). Для Санкт-Петербурга с его масштабным историко-культурным и архитектурным наследием, являющимся важнейшим элементом идентичности горожан, общественные движения по его защите играли важную роль. Деятельность таких объединений, как «Группа спасения», «Живой город» и других гражданских инициатив, возглавляемых профессионалами от культуры, истории и краеведения, стала неотъемлемой частью локальной городской повестки (Гладарев 2011) и заложила основу градозащитного активизма. Большая часть этих действий была направлена против застройки или в защиту исторических зданий от сноса (Тыканова 2013; Тыканова, Хохлова 2014). Именно «охранный» и даже протестный модус долгое время казался единственно возможным для городского активизма, и в его основе неизбежно лежал конфликт (Гладарев 2011; Клеман и др. 2010: 78-79).

В 2010-х гг. в Петербурге стал набирать популярность другой вид низового городского активизма- «созидательный» (Королева, Чернова 2018:93). Первые подобные инициативы касались экологии (движение «Мусора больше нет») и развития велоинфраструктуры-инициатива Let's bike it (Фатыхова 2017: 110, 184; Make Make 2012). В их основе лежала идея о том, что город принадлежит горожанам, имеющим право менять его. В 2010-х крупные российские города наполнились множеством проектов в духе «делай сам» DIY (Фатыхова 2017; Королева, Чернова 2018: 93-94); приобрели популярность микроинтервенции в стиле «тактического урбанизма» (Лайдон, Гарсиа 2019). Активные горожане внедряли отсутствующие элементы городской инфраструктуры и новые способы времяпрепровождения, трансформируя привычную жизнь публичных пространств (Москалева, Тыканова 2016). Эти инициативы, с одной стороны, позволяли 
производить небольшие, но востребованные изменения в городской среде, а с другой стороны, влияли на самоощущение активистов, начавших осознавать свои возможности по трансформации городов. Движение DIY стало важным этапом и первым шагом на пути к развитию «нового городского активизма»- превращению вчерашних «обывателей» в сознательных «горожан» (Клеман и др. 2010).

В 2012 г. разрозненные петербургские «созидательные» городские инициативы (создающие самодельные велодорожки, арт-объекты, городскую мебель, городские огороды) впервые объединились для участия в недельном марафоне «Делай сам». Это событие можно считать началом новой волны активизма в Петербурге, поскольку оно сыграло важную роль в налаживании связей между активистами и в осознании ими своих возможностей.

\section{Фестивализация и новая атмосфера городского активизма}

Для НГА характерны форматы деятельности, отличающиеся от тех, что присущи протестным и градозащитным движениям. Новые городские активисты используют «мягкие методы»: добиваются целей за счет формирования ценностей и добавления новых смыслов, а не за счет прямого противостояния и борьбы. Их проекты отличает изобретательность, притягательность, легкость, ирония и эстетизация (Архсовет Москвы 2015; Pachenkov, Voronkova 2013a,b). Они не агитируют, не взывают «к совести», но стремятся создать моду на явления, которые хотят видеть в своих городах. Благодаря этой непринужденности привлекают и побуждают к действиям большое количество самых разных людей. Например, проведение фестивалей стало распространенной формой влияния на городские изменения.

В 2016-2018 гг. в Петербурге прошла целая серия фестивалей, объединявших представителей разных инициатив, например, «Живые улицы» (2016, 2017, 2018), «Твоя вода» (2017), «Твой двор» $(2017,2018)$, «Сегодня можно» (2018), конфест «Активиз/мы» (2019). Сохраняя форму городского праздника, фестивали активистов стремились не сводить происходящее к массовому развлечению, они запускали новые процессы и формировали новые запросы со стороны горожан, например, на общественные пространства или интерактивные, содержательные, развивающие, а не пассивные, формы проведения досуга в городской среде.

«Фестивали», «мастерские», «воркшопы» и подобные созидательные форматы создают иную атмосферу и эмоциональный регистр, характерный для НГА: это скорее ощущение удовольствия, хеппенинга, нежели свойственные градозащитному движению мобилизация воли и чувства долга. Лейтмотив новых городских активистов: «Активизм- это стильно! Mbl делаем город живым, гуманным, экологичным, разнообразнымм (Город 2019); свои события они описывают так: «[конфест] Это не скучная конференция, а умный фестиваль супергероев» (там же). 


\section{Созидательная логика действия \\ в новом городском активизме}

Разделяя городские инициативы на «протестные» или «защитные», с одной стороны, и «созидательные», с другой, мы говорим об «идеальных типах». В фактической деятельности эти модусы могут сочетаться. Однако инициативы активистов новой волны отличает доминирование именно созидательной логики: даже если имеют место защитные или протестные действия, они, как правило, носят характер промежуточных, не меняя в целом созидательного вектора всего проекта.

В качестве примера приведем инициативу по развитию общественных пространств на набережной Карповки в одном из центральных районов Петербурга. Часть территории реки несколько десятилетий служила для хранения частных лодок и катеров, была окружена забором и закрыта для посторонних. Группа активистов предложила районной администрации открыть этот участок набережной и создать общественное пространство доступное для всех. С первых дней обсуждения концепции развития территории они не выступали против «захватчиков территории», но наоборот - предлагали варианты сохранения лодок и катеров как специфичного аттрактора и элемента идентичности этого места, связывающего его с водой. Инициаторы развития набережной, назвавшиеся «Друзья Карповки», организовывали встречи и события, привлекали широкий круг заинтересованных, включая владельцев лодок и катеров, к участию в обсуждении проекта благоустройства набережной. Инициатива начиналась как «созидательная». Однако в процессе создания проекта благоустройства появилась протестная составляющая: городские ведомства выявили на территории множество деревьев, подлежащих вырубке; это вызвало протест участников экологических движений, частично входивших в «Друзья Карповки», и стремившихся сохранить деревья. Протест активистов вокруг уничтожения деревьев вылился в альтернативное решение: они нашли сертифицированных специалистов и провели независимую экспертизу; последовательно продвигая «зеленую» повестку, убедили чиновников и проектировщиков внести изменения в проект. Таким образом, активисты использовали протестные практики для защиты деревьев, но в результате предложили свой вариант решения проблемы в «созидательном» формате.

Другой пример - движение в защиту парка на реке Смоленке. Классическая активность «против» застройки набережной преобразована в инициативу «за» парк (Митинг ЗА парк 2018). Добившись запрета на строительство, активисты, среди которых были архитекторы и урбанисты, стали действовать в духе созидательного нового городского активизма и разработали собственную концепцию развития набережной для продолжения конструктивного диалога с городскими чиновниками. 
Схожая история произошла еще с одной инициативой, начавшейся с протестов против строительства автомобильной магистрали вдоль Финского залива, постепенно трансформировавшейся в инициативу «За берег» (\#Заберег 2019). Активисты инициировали создание рабочей группы по вопросу благоустройства береговой линии при Администрации Красносельского района Петербурга. В эту группу вошли чиновники, активисты и привлеченные ими архитекторы. Совместно они разработали альтернативное «общественное техническое задание» на проектирование береговой линии, которое было передано проектировщику. Такая трансформация от вектора «против» к вектору «за» присуща не только группам, но и индивидуальным активистам.

\section{Установка на сотрудничество}

Новые городские активисты готовы к кооперации с широким кругом акторов, если это способствует достижению целей и соответствует их ценностям. Городская исполнительная власть и девелоперы как значимые агенты городских изменений выступают для новых активистов стороной в переговорах, а не оппонентами в ситуации конфронтации, что характерно для градозащитников. Активисты ищут подобного диалога, превыше всего ценя возможность реализации своих идей, т.е., в конечном счете-возможность появиться в городской среде чему-то важному:

Я позвонила [другому активисту движения], говорю: «Слушай, к нам приезжает $N$, надо хватать его за уздцы и проталкивать эту идею». <... На тот момент $N$ был ВРИО губернатора; нам бы, конечно, не очень хотелось, чтобы он становился губернатором. Но мы понимали, что мы должны общаться, вот... что мы имеем, то мы имеем. И с этим мы должны находить взаимодействие и общий язык (активист движения \#За берег).

Продуктивное сотрудничество требует от активистов понимания принципов работы властных структур и бизнеса. Они постоянно повышают свои компетенции и применяют это знание, по-своему манипулируя существующей «бюрократической машиной» и процедурами принятия решений в интересах тех проектов городского развития, в которые верят и которые стремятся реализовать:

...ты должен понимать, что, либо ты вписываешься в эту систему и думаешь, как вот в ней работать, либо ты будешь очень сильно тормозить. <... Я подстроилась под всю систему вот эту выстроенную в городе, для того чтобы добиться своей цели (активист движения «Деревья Петербурга»).

Мы бы хотели подчеркнуть при этом, что в НГА речь не идет о «беспринципности». Несмотря на прагматическую ориентацию, важнейшим условием деятельности новых городских активистов является следование базовым ценностным установкам, среди которых: качество городской среды, бережное отношение к городской природе, уважение жителей 
и даже форм жизни. В этих вопросах новые активисты не склонны идти на компромиссы, готовы убеждать и переубеждать, применять методы тактического урбанизма, далеко не всегда согласованные и легальные, но легитимные в их глазах с точки зрения значимых для них (и города, и горожан) ценностей. Новые активисты не считают себя «коллаборационистами»; отдавая себе отчет в том, что часто вынуждены сотрудничать с людьми, с которыми не разделяют многие ценности, стремятся быть максимально честными и публичными, для того, чтобы их целеполагание и методы работы стали прозрачны и очевидны. Вот как презентует себя вовне известная городская активистка:

За шесть лет работы с городским пространством мне повезло найти замечательных людей и вместе создать яркие, сложные и важные проекты $<\ldots>$ одновременно выстраивая отношения с администрацией, «официальной» структурой принятия решений, и не предавая того, во что верю. А верю я в нас с вами-в то, что, развивая гражданское общество, где каждый берёт на себя ответственность за происходящее вокруг и принимает решение делать, мы будем жить в другом городеактуальном, удобном, доступном для всех, экологически безопасном и эстетическим прекрасном (Твой бюджет... 2019).

\section{От «аполитичности»- к новой публичной политике}

Помимо анализа специфических черт, характеризующих НГА «изнутри», в заключении мы хотели бы рассмотреть его в более широком социально-политическом контексте. Какую роль играет НГА в контексте жизни современного российского общества? Для ответа на этот вопрос обратимся к сюжету об «аполитичности» современного российского общества (Замятин 2020) активно обсуждаемой, в том числе исследователями активизма (Клеман и др. 2010; Ерпылева, Магун 2014; Тыканова, Хохлова, 2017).

Городские активисты традиционно противопоставляют город и политику, рассматривая городское пространство скорее как «культурный» феномен, нежели «политический». Борис Гладарев упоминает манифест «Культура вместо политики», написанный ленинградскими градозащитниками, и указывает на то, что подобно своим предшественникам 1920-х гг., защитники наследия конца 1980-х подчеркивали аполитичность своего движения (Гладарев 2011: 112). Исследователи медиа нередко упрекают новых городских активистов в том, что вместо участия в политических институтах (таких, как выборы) и институтах контроля власти (таких, как митинги), они отдают предпочтение «малым делам», условным «субботникам», направленным не на критику и смену власти, а на изменение городской среды своими силами (Полищук 2015). Их деятельность иронично именуют «хипстерской урбанистикой» (Вахштайн 2014; Сошников 2013), описываемой как «аполитичная модернизация всего, что не угрожает режиму собственно 
политическими изменениями» (Панеях 2019). Мы же утверждаем, что НГА способствует изменениям политического поля в современной России и переопределению самого понятия «политического» и «политики». Однако чтобы понять, чем является деятельность городских активистов в этом контексте, важно начать с определения «политического».

Большую часть XX в. «политика» ассоциировалась с «реальной» политикой в понимании Карла Шмитта (1992), она понималась как пространство борьбы за власть против «врага», «политического оппонента». Эту разновидность политики часто представляют как единственно возможную и отказ от участия в ней трактуют как аполитичность. Ханна Арендт (2000) показала, что возможно иное понимание политики и другое пространство политической деятельности, осуществляемой по иным принципам. Она обращается к политике в античном смысле и обнаруживает принципиальные отличия от шмиттовской трактовки: «[б]ыть политическим, жить в полисе означало, что все дела улаживаются посредством слов, способных убедить, а не принуждением или насилием» (Арендт 2000: 37); и далее:

все понимаемое нами под господством и порабощением, под властью, государством и правлением, короче все наши концепции политического порядка считались наоборот дополитическими; они имели себе оправдание не в общественном, но в частном, и были в собственном смысле слова неполитическими- к полису не относящимися (там же: 43).

В Новое время, полагает Арендт, произошла «приватизация» публичной сферы, а политика отделилась от нее, стала приравниваться к государственной деятельности-в интересах государства и внутри его институтов. Так политическая деятельность фактически заменилась хозяйственной (там же: 39). Под политикой стала пониматься борьба за власть и экономические ресурсы в целях контроля над хозяйственной деятельностью в рамках национального государства, осуществляемая с опорой на свойственные государственной машине принуждение и насилие. Именно такое понимание политики стало доминирующим.

Мы же полагаем, что в последние десятилетия наблюдается «структурная трансформация» политического поля, а именно возрождение «публичной политики», которая была утрачена в Новое время, и НГА играет в этом процессе существенную роль. Античная политика, по мнению Арендт конституировалась двумя основными элементами- «деянием» и «публичностью». В эпоху, когда стремление совершить деяние все больше ассоциируется с тщеславием (там же: 72), вторая составляющаяпубличность - особенно актуальна, поскольку становится едва ли не единственным условием «политического бессмертия», все еще доступного гражданам. Развитие и укрепление публичной сферы фактически можно считать новой политикой, формирующей альтернативу «реальной» политике, осуществляемой в государственной сфере. 
Согласно Арендт, «увиденность и услышанность другими» (там же: 75) нужны для взаимного понимания и (взаимо)действия, для активного (co) существования людей. Публичная сфера является тем пространством, где это становится возможно. Общение, диалог с другими, заведомо отличными от тебя людьми и совместное (но не «коллективное») действие свободных и мыслящих индивидов- конституируют публично-политическую сферу, обеспечивающую форму (со)существования, достойную человека. Мы полагаем, что поскольку именно ценности, связанные с коммуникацией в публичной сфере, с возможностью вести диалог с «другими» отличающимися людьми, играют существенную роль в деятельности новых городских активистов, их можно считать значимыми участниками процесса строительства новой публичной сферы и одновременно участниками новой- публичной- политики. Городские активисты формируют новый тип «горожанина-гражданина»- «человека публичного», который озабочен общими вещами (res publica) и общественным благом, в интересах которого готов действовать совместно с другими людьми. Не случайно формула «от жителя-к горожанину» или «от горожанинак гражданину» регулярно фигурирует в дискурсе нового городского активизма (см.: Мышленникова, Еренк 2013; Международный форум пространственного развития 2018; Мурунов 2019). Эти формулы указывают на процесс осознания новыми городскими активистами себя в отношении к формирующемуся пространству публичной политики.

Новая публичность и новая политика начинают складываться вокруг города и его пространства. Благодаря своему разнообразию, город обеспечивает необходимую для этой разновидности политического действия «питательную среду» и инфраструктуру в виде публичных пространств. Он становится тем масштабом и тем пространством, где новая публичная политика разворачивается в условиях монополии элит на доступ к институтам государственной политики, от которой большинство граждан отчуждены. Вдобавок, в условиях атомизации, диверсификации стилей жизни и девальвации ранее значимых ценностей, способных объединить общество, городское пространство рассматривается как наиболее очевидное, понятное и осязаемое общественное благо, в отношении которого индивид может совершить осознанное действие, способное что-то изменить. Речь идет не просто об «общей вещи» (res publica), но именно об «общем месте» в буквальном пространственном смысле слова, и в этом пространственном качестве город становится основой для объединения, для диалога и гражданского действия. Борис Гладарев, пользуясь терминологией Лорана Тевено, пишет об этой специфической роли городского пространства в современном российском обществе, где публичность конструируется средствами особой разновидности «политической грамматики», которую он называет грамматикой «близости через «общие места»» (Гладарев 2011:277). 
Таким образом, городское пространство, являясь общественным благом, «общим местом» и территорией осуществления публичной жизни - становится основой новой российской politika производной от polis, публичной политикой города, творимой силами свободных горожанграждан, все яснее осознающих себя в качестве таковых; поэтому роль именно городских активистов в этом процессе особенно важна.

\section{Заключение}

На примере городского активизма в Санкт-Петербурге мы показали трансформацию этого явления в последние годы. По нашему мнению, одной из важнейших черт происходящих изменений является сдвиг от «охранительного» вектора, характерного для градозащитного городского активизма предыдущих волн (включая, движения начала 2000-х) в сторону «созидательного». Этот переход сопровождается изменениями в форматах деятельности, к которым обращаются новые городские активисты - в частности, популярностью инструментов DIY, «тактического урбанизма» и фестивалей как формы публичных мероприятий, пришедших на смену пикетам и акциям протеста. Для «созидательных» городских активистов характерна ориентация на сотрудничество с широким кругом акторов, среди которых представители исполнительной власти и бизнесате, с кем градозащитники скорее вступают в жесткую конфронтацию. Таким образом, мы считаем возможным говорить о качественном сдвиге в сфере активизма и о формировании его новой волны, которую мы назвали «новым городским активизмом».

Безусловно, прежние формы городского активизма не исчезли, и сегодня «протестные», «защитные» и «созидательные» городские инициативы сосуществуют; тем не менее мы отмечаем, что с 2010-х гг. созидательный вектор активизма, связанный с трансформацией городской среды, стал доминировать, фактически изменив повестку городского активизма, по крайней мере в Петербурге. Мы ставим под сомнение распространенный тезис об аполитичности новых городских активистов. Предложенное Арендт понимание «политического» позволяет нам утверждать, что, даже не принимая участия в «реальной» политике, городские активисты своими действиями формируют новый сегмент поля «политического»- публичную политику, которая схожа с античным пониманием политической деятельности. Это сходство тем очевиднее, когда основной точкой приложения политических усилий вновь становится город-polis; тем самым в деятельности городских активистов politika обретает свой исконный смысл, становясь публичной деятельностью на благо города. Таким образом, благодаря популярности НГА, политики в жизни российских городов становится не меньше, но больше, точнее- больше различных «политик». 


\section{Выражение признательности}

Редакция благодарит программу «Университетское партнерство» за поддержку и возможность опубликовать данную статью.

\section{Материалы для анализа}

Make Make (2012) Делай Сам в четвертый раз. Доступно по ссылке: http://partizaning. $\operatorname{org} / ? \mathrm{p}=4590$ (дата обращения: 1 октября 2020).

Архсовет Москвы (2015) Городские активисты: Партизанинг и СовАрх. Дотсупно по ссылке: https://archsovet.msk.ru/article/gorod/gorodskie-aktivisty-partizaning-i-sovarh (дата обращения: 1 октября 2020).

Город (2019) Конфест активиз/мbl. Доступно по ссылке: http://project1771161.tilda. ws/ (дата обращения: 30 марта 2021).

\#ЗАберег (2019) Защитим Жемчужный берег. Доступно по ссылке: https://vk.com/ za_bereg (дата обращения: 1 октября 2020).

Международный форум пространственного развития (2018) Секция Житель-горожанин-гражданин: как меняется управление и экономика города в условиях ицифрового мира. Доступно по ссылке: https://www.facebook.com/isdforum/ (дата обращения: 1 октября 2020).

Митинг ЗА парк (2018) Доступно по ссылке: https://vk.com/miting_ps (дата обращения: 30 марта 2021).

Мурунов С. (2019) Кто мы? Проблемы идентичности постсоветского человека. Житель-горожанин-гражданин. Как город влияет на нас, а мь--на город. Доступно по ссылке: https://www.artoknofest.ru/events/121 (дата обращения: 1 октября 2020).

Мышленникова Д., Еренк Э. (2013) От жителя- к горожанину. Новые форматы городской гражданской культуры. Доступно по ссылке: https://www.grany-center. org/sites/default/files/user-20/buklet_okt13_print.pdf (дата обращения: 1 октября 2020).

Панеях Э. (2019) Просвещенный урбанизм и сапоги на клумбах. Ведомости. Мнения. Ааналитика. Доступно по ссылке: https://www.vedomosti.ru/opinion/columns/2019/08/15/808821-prosveschennii-urbanizm (дата обращения: 30 марта 2021).

Твой бюджет (2012) Петроградский район. Модератор. Доступно по ссылке: https:// vk.com/tb_petro?w=wall-147074611_174 (дата обращения: 1 октября 2020).

Сошников А. (2013) Хипстерский урбанизм: сладкая вата и пуфики вместо решения реальных проблем? Мой район. Доступно по ссылке: https://mr-7.ru/articles/91009/ (дата обращения: 30 марта 2021).

\section{Список источников}

Арендт Х. (2000) Vita activa, или о деятельной жизни. СПб.: «Алетейя».

Вахштайн В. (2014) Пересборка города: между языком и пространством. Социология власти, (2): 9-38.

Гладарев Б. (2011) Историко-культурное наследие Петербурга: рождение общественности из духа города. О. Харахордин (ред.) От общественного к публичному. СПб.: изд-во ЕУСПб: 71-304. 
Ерпылева С. В., Магун А.В. (ред.) (2014) Политика аполитичных: гражданские движения в России 2011-2013 годов. М.: НЛО.

Замятин А. (2020) За демократию: местная политика против деполитизации. М.: Издательские решения.

Здравомыслова Е.А. (1990) Социологические подходы к анализу общественных движений. Сочиологические исследования, (7): 88-94.

Здравомыслова Е. А. (1993) Парадигмы западной социологии общественных движений. СПб.: Наука.

Клеман К., Мирясова О., Демидов А. (2010) От обывателей к активистам. Зарождающиеся сочиальные движения в современной России. М.: Три квадрата.

Королева М.Н., Чернова М. А. (2018) Городской активизм: управленческие практики как ресурс и барьер развития городских проектов. Социологические исследования, (9): 93-101.

Лайдон М., Гарсиа Э. (2019) Тактический урбанизм: краткосрочные действиядолгосрочные перемены. М.: Strelka Press.

Москалева С.М., Тыканова Е. В. (2016) Социальные условия деятельности гражданских и экспертных групп по улучшению качества городской среды. Журнал социологии и сочиальной антропологии, (4): 103-120.

Полищук Л. (2015) Ждать начальства или скинуться самим: социальный капитал в жизни города. В. Аузан (ред.) Стимуль, парадоксы, проваль: Город глазами экономистов. М.: Strelka Press: 113-135.

Романов П. В., Ярская-Смирнова Е. Р. (ред.) (2009) Общественные движения в России: точки роста, камни преткновения. М.: Вариант.

Тыканова Е.В. (2013) Стратегии и тактики оспаривания городского пространства группами интересов (на примере конфликтов вокруг городского развития в СанктПетербурге). Вестник Санкт-Петербургского университета, 12 (1): 108-115.

Тыканова Е.В., Хохлова А. М. (2014) Траектории самоорганизации локальных сообществ в ситуациях оспаривания городского пространства. Социология власти, (2): 104-122.

Тыканова Е.В., Хохлова А.М. (2017) Между политическим и аполитичным: формы участия локальных сообществ в защите городских территорий. В.П. Мохов (ред.) Современный город: власть, управление, экономика. Пермь: Изд-во ПНИПУ:218-236. Фатыхова Н. (ред.) (2017) Делай сам/а. Практики низовых гражданских инициатив. М.: Перо.

Халий И.А. (2007) Современные общественные движения: инновационный потенииал российских преобразований в традиционалистской среде. М.: Институт социологии РАН.

Шмитт К. (1992) Понятие политического. Вопросы социологии, (1):37-67.

Pachenkov O., Voronkova L. (2013 a) Urban Public Space in the Age of Mobility and Aestheticization, and the Necessity of an Interdisciplinary Approach. In: O. Pachenkov (ed.) Urban Public Space. Facing Challenges of Mobility and Aestheticization. Frankfurt am Main: Peter Lang: 13-30.

Pachenkov O., Voronkova L. (2013b) Reclaiming the (High) Modern City Space: An Aesthetic Dimension. In: E. T. Bertuzzo, E. B. Gantner, J. Niewöhner, H. Oevermann (eds.) Kontrolle öffentlicher Räume. Unterstützen Unterdrücken Unterhalten Unterwandern. Berlin: LIT Verlag:222-231. 
Oleg Pachenkov, Lilia Voronkova

\title{
'NEW URBAN ACTIVISM' AND 'PUBLIC POLICY' IN RUSSIA (CASE OF SAINT PETERSBURG)
}

\begin{abstract}
In the recent decade, specialists observe a growth - in number and scale- of all sorts of grass root activities connected to the urban development and urban environment in contemporary cities. By these activities we mean a growing popularity of DIY movements and projects, a growth of demand for horizontal (non-hierarchical) connections, forms of actions and organization, a popularity of various participatory mechanisms. Our 10-years long observation (form inside as consultants for activist groups, and from outside as researchers) allows distinguishing several common vectors in the transformation of grass root urban activist movements in the recent years. We identify, for instance, a transformation from protective 'initiatives against' to the productive 'initiatives for', from struggle to cooperation. We argue that these transformations constitute a phenomenon we call the new urban activism. Drawing from interviews with urban activists of Saint Petersburg, as well as from our observation of their projects, we show how dramatism of protective urban activism has transformed - via DIY and tactical urbanism movements popular in Russian cities in the early 2000s - into a rather festive and joyful activity. In the last part, we also address the issue of 'political apathy.' To conceptualize observed processes, we employ the theoretical approach suggested by Hanna Arendt. We look at the activity of the new urban activism through the perspective of vita activa and argue that the new activism constitutes a sphere of public policy, as an alternative to the conventional Realpolitik, reminding politika that refers to an ancient polis where city was the main concern of citizens.
\end{abstract}

Key words: activism, city, politics, public sphere, public space, urbanism

DOI: 10.17323/727-0634-2021-19-2-253-268

\section{References}

Arendt H. (2000) Vita activa, ili o deyatel'noy zhizni [The Human Condition]. St. Petersburg: Aleteyya.

Clemant K., Miryasova O., Demidov A. (2010) Ot obyvateley k aktivistam. Zarozhdayushchiesya sotsial 'nye dvizheniya v sovremennoy Rossii. [From Inhabitants to Activists. Emerging Social Movements in Contemporary Russia]. Moscow: Tri kvadrata.

Oleg Pachenkov- Cand. Sci. (Sociol.), Project leader, the Center for Urbanism and Participation 'UP', European University at Saint Petersburg, Russia. Email: pachenkov@yahoo.com

Lilia Voronkova- Leading Researcher at the Center for Independent Social Research, Saint Petersburg, Russia. Email: 1ilia.voron@gmail.com 
Erpyleva S. V., Magun A. V. (eds.) (2014) Politika apolitichnykh: grazhdanskie dvizheniya v Rossii 2011-2013 godov [Politics of Apolitical. Civic Movements in Russia in 20112013]. Moscow: NLO.

Fatykhova N. (ed.) (2017) Delay sam/a. Praktiki nizovykh grazhdanskikh initsiativ [Do it Yourself. Practices of Grass Root Inititives]. Moscow: Pero.

Gladarev B. (2011) Istoriko-kul'turnoe nasledie Peterburga: rozhdenie obshchestvennosti iz dukha goroda [Historical and Cultural Heritage of Saint Petersburg: Birth of Public from the Spirit of the City]. In: O. Kharakhordin (ed.) Ot obshchestvennogo k publichnomu [From Obshchestvennoe to the Public]. St. Petersburg: EUSP: 71-304.

Khaliy I.A. (2007) Sovremennye obshchestvennye dvizheniya: innovatsionnyy potentsial rossiyskikh preobrazovaniy v traditsionalistskoy srede [Contemporary Civic Movements: Innovative Potential of Transformations in Russian Traditionalist Environment]. Moscow: Institut sotsiologii RAN.

Koroleva M.N., Chernova M.A. (2010) Gorodskoy aktivizm: upravlencheskie praktiki kak resurs i bar'er razvitiya gorodskikh proektov [Urban Activism: Management Practices as a Resource and a Barrier for the Development of City Projets]. Sotsiologicheskie issledovaniya [Sociological Research], (9): 93-101.

Laydon M., Garcia E. (2019) Takticheskiy urbanizm: kratkosrochnye deystviya-dolgosrochnye peremeny [Tactical Urbanism: Short-Term Actions for Long-term Change]. Moscow: Strelka Press.

Pachenkov O., Voronkova L. (2013 a) Urban Public Space in the Age of Mobility and Aestheticization, and the Necessity of an Interdisciplinary Approach. In: O. Pachenkov (ed.) Urban Public Space. Facing Challenges of Mobility and Aestheticization. Frankfurt am Main: Peter Lang Verlag: 13-30.

Pachenkov O., Voronkova L. (2013b) Reclaiming the (High) Modern City Space: An Aesthetic Dimension. In: E. T. Bertuzzo, E. B. Gantner, J. Niewöhner, H. Oevermann (eds.) Kontrolle öffentlicher Räume. Unterstützen Unterdrücken Unterhalten Unterwandern. Berlin: LIT Verlag: 222-231.

Polishchuk L. (2015) Zhdat' nachal'stva ili skinut'sya samim: sotsial'nyy kapital v zhizni goroda [To Wait for Bosses or Co-fund Ourselves]. In: V. Auzan (ed.) Stimuly, paradoksy, provaly: Gorod glazami ekonomistov [Impetuses, Paradoxes, Fails: City by the Eyes of Economists]. Moscow: Strelka Press: 113-135.

Romanov P. V., Yarskaya-Smirnova E.R. (eds.) (2009) Obshchestvennye dvizheniya v Rossii: tochki rosta, kamni pretknoveniya [Civic Movements in Russia: Points of Increase, Stumbling Rocks]. Moscow: Variant.

Schmitt C. (1992) Ponyatie politicheskogo [Der Begriff des Politischen]. Voprosy sotsiologii [Sociology Issues], (1):37-67.

Tykanova E. V. (2013) Strategii i taktiki osparivaniya gorodskogo prostranstva gruppami interesov (na primere konfliktov vokrug gorodskogo razvitiya v Sankt-Peterburge) [Strategies and Tactics of Contestation of City Space by the Interest Groups (Case of Conflicts around Urban Development of Saint Petersburg]. Vestnik Sankt-Peterburgskogo universiteta [Herald of Saint Petersburg University], 12 (1): 108-115. 
Tykanova E. V., Khokhlova A. M. (2014) Traektorii samoorganizatsii lokal'nykh soobshchestv v situatsiyakh osparivaniya gorodskogo prostranstva [Trajectories of Self-organization in the Situations of Contestation of City Space]. Sotsiologiya vlasti [Sociology of Power], (2): 104-122.

Tykanova E. V., Khokhlova A. M. (2017) Mezhdu politicheskim i apolitichnym: formy uchastiya lokal'nykh soobshchestv v zashchite gorodskikh territoriy [Between Political and Apolitical: Forms of Participation of Local Communities in the Protection of City Territories]. In: V.P. Mokhov (ed.) Sovremennyy gorod: vlast', upravlenie, ekonomika [Contemporary City: Power, Governance, Economics]. Perm': Izd-vo PNIPU:218-236.

Vakhshtayn V. (2014) Peresborka goroda: mezhdu yazykom i prostranstvom [Reassembling the City: Between Language and Space]. Sotsiologiya vlasti [Sociology of Power], (2): 9-38.

Zdravomyslova E. A. (1990) Sotsiologicheskie podkhody k analizu obshchestvennykh dvizheniy [Sociological Approaches to the Analysis of Social Movements]. Sotsiologicheskie issledovaniya [Sociological Research], (7): 88-94.

Zdravomyslova E. A. (1993) Paradigmy zapadnoy sotsiologii obshchestvennykh dvizheniy [Paradigms of Western Social Sceince on Social Movements]. St. Peterburg: Nauka. 